\title{
Reuna
}

\section{PRÁTICAS DE ESPIRITUALIDADE: UM CAMINHO PARA O BEM-ESTAR DE JOVENS TRABALHADORES}

\author{
PRACTICE OF SPIRITUALITY: A WAY FOR THE WELFARE OF YOUNG WORKERS \\ http://dx.doi.org/10.21714/2179-8834/2017v22n2p24-43
}

\begin{abstract}
Elisângela Julião Cardoso
Universidade Salvador (Unifacs), Brasil.

E-mail: elisangela_juliao@yahoo.com.br
\end{abstract}

\author{
Jair Nascimento Santos \\ Universidade Salvador (Unifacs) e Universidade do Estado da Bahia, Brasil. \\ Endereço: Rua Silveira Martins, 2555 - Cabula - Salvador - BA \\ Fone: +55 (91) 3117-2200 \\ E-mail: jair.santos@unifacs.br
}

Submissão: 17 Mar. 2017 Publicação: 23 set. 2017. Sistema de avaliação: Double blind review. Centro Universitário UNA, Belo Horizonte - MG, Brasil. Editor geral: Prof. Dr. Gustavo Quiroga Souki

Este artigo encontra-se disponível nos seguintes endereços eletrônicos:

http://revistas.una.br/index.php/reuna/article/view/896

http://dx.doi.org/10.21714/2179-8834/2017v22n2p24-43

\section{RESUMO}

O trabalho se tornou algo inerente ao indivíduo e está presente em sua vida desde os tempos remotos da humanidade. A forma como tem sido executado, lastreado na máxima racionalidade e desconsiderando o trabalhador em suas subjetividades, finda por causar uma série de mazelas ao executor do trabalho. Assim, de modo a enxergar o indivíduo na sua completude (objetividade e subjetividades), a espiritualidade tem adentrado as organizações e suas práticas têm se tornado uma alternativa para retomar no indivíduo o sentido do trabalho. Nesse sentido, a pesquisa teve como objetivo verificar as relações entre as práticas de espiritualidade e o valor organizacional - bem-estar, a partir da percepção de jovens trabalhadores. De cunho quantitativo, esta pesquisa se utilizou da matriz de correlações e das estatísticas descritivas, para alcançar o objetivo do estudo. Assim, na coleta de dados foi utilizado um questionário estruturado, disponibilizado através da internet, para instituições que trabalhavam com a atividade de aprendizagem e capacitação de jovens com idade entre 18 e 24 anos, no território nacional, a fim de que este fosse aplicado com os jovens participantes do programa. Foram obtidos 406 questionários válidos. Os resultados apontaram que os jovens percebem que as práticas de espiritualidade relativas à diminuição da carga de trabalho, valorização do funcionário e exercício da espiritualidade, que possuem uma forte associação com o valor organizacional relativo ao bem-estar, considerando que as práticas de espiritualidade listadas podem contribuir para a consecução do bem-estar do jovem trabalhador.

Palavras-chave: Espiritualidade, Bem-Estar, Jovem Trabalhador 


\begin{abstract}
The work became something inherent in the individual and is present in your life since ancient times of mankind. The way it has been executed, ballasted to the maximum rationality and disregarding the worker in their subjectivities, leading to cause a series of ills to the performer of the work. So, in order to see the individual in your completeness (objectivity and subjectivity), spirituality has entered organizations and practices have become an alternative to resume in person the meaning of the work. In this sense, the objective of this research is to find out how spiritual practices can contribute to achieving the well-being of young workers. Quantitative measures, this study used the descriptive statistics and correlations, to achieve the objective of the study. Thus, in the collection of data, structured questionnaire was used, made available through the internet, to institutions working with the learning activity and training of young people aged between 18 and 24 years, in the national territory in order that they were applied with the young participants of the program. 406 valid questionnaires were obtained. The results showed that young people realize that spiritual practices, relating to: decrease the workload, employee appreciation and practice of spirituality, have a strong association with the organizational value on the well-being, whereas spirituality practices lists, can contribute to achieving the wellbeing of the young worker.
\end{abstract}

Keywords: Spirituality, wellness, young worker

\title{
1 Introdução
}

O indivíduo tem no trabalho algo inerente ao seu ser e este entendimento percorre longos anos da existência humana. Por conta disso, o trabalho foi assumindo significados diferentes em cada época, houve períodos em que foi considerado como meio de sobrevivência, outros períodos como atividade relacionada à escravidão, até alcançar o patamar de uma lógica advinda da máxima eficiência e extrema racionalidade, a fim de conduzir a maximização dos lucros para as organizações e minimização da qualidade de vida para os funcionários. Desse modo, o que se percebeu no decorrer dos tempos foi que uma série de mazelas físicas, sociais e psíquicas passa a acometer os trabalhadores, levando a esses a ideia de que o local de trabalho proporciona sofrimento e supressão da condição humana (CHANLAT, 1996; SENNET, 2009; VERGARA; MOURA, 2012).

Ao tornar as tarefas muito mais repetitivas e rotineiras, as organizações foram retirando dos trabalhadores a autonomia na "construção de suas realidades", pois à medida que apenas sua condição racional era vista no ambiente laboral, todas as dimensões, que compunham o indivíduo, passaram a ser ignoradas, esquecidas. A subjetividade, que traduz ao indivíduo as características de "personalidade, expectativas, medos, alegrias, tristezas, e demais singularidades e imperfeições" da sua condição humana foi a que mais ficou esquecida no processo de implantação das atividades industriais (CHANLAT,1996; SENNET, 2009; VERGARA; MOURA, 2012). É nesse contexto que a espiritualidade organizacional busca se estabelecer com o intuito de considerar o indivíduo-trabalhador como detentor de múltiplas dimensões, respeitando suas necessidades emocionais, espirituais e, também, racionais. A espiritualidade organizacional pode ser compreendida como o ato de reconhecer que o trabalhador possui uma vida interior, que necessita ser nutrida a partir de uma 
atividade laboral com significado e que proporcione uma sensação de pertencimento à comunidade (ASHMOS; DUCHON, 2000).

A exigência por uma gestão mais humanizada e por fim, espiritualizada no âmbito das organizações surge como uma necessidade do milênio atual. Contudo, a implantação deste novo modelo gerencial, ainda causa receio entre os gestores, pelo fato de não haver ferramentas que os norteiem, sem contar com o preconceito que vigora acerca do tema, ao se comparar a espiritualidade com a religião (FRESHMAN,1999; MITROFF, 2000).

Nesse contexto, sugere-se que para espiritualizar as organizações de modo a satisfazer os trabalhadores e, consequentemente, obter maior eficácia nas tarefas e elevação da produtividade, algumas práticas são indicadas como: a) exercício da espiritualidade; b) valorização do funcionário; c) diminuição da competição interna; e d) diminuição da carga de trabalho (BEZERRA; OLIVEIRA, 2007; DANIEL, 2010).

Se a espiritualidade se torna uma meta organizacional, é possível que esta passe a ter influência nos valores organizacionais. Isto porque, conforme afirmam Tamayo e Gondin (1996), bem como Oliveira e Tamayo (2004), os valores organizacionais representam as percepções dos trabalhadores sobre os princípios e crenças que vigoram na organização.

A relevância de estudar as relações entre as práticas de espiritualidade e o valor organizacional - bem-estar relacionado ao jovem trabalhador, se debruça no fato de que há poucas pesquisas pertinentes ao jovem no meio corporativo, em âmbito nacional, ainda que se saiba que essa fase da vida pode apresentar soluções muito significativas para a sociedade (OIT, 2009).

A pesquisa sobre as práticas de espiritualidade organizacional assume importância à medida que, internacionalmente, as discussões sobre esse tema avançam de forma célere, enquanto que no Brasil caminha a passos curtos (ANPAD; Scielo, SPELL). Estudos apontam que a espiritualidade pode contribuir para reduzir a precariedade nas condições do trabalho à medida que busca dar significado ao trabalho, além de alegria e senso de pertencimento comunitário (ASHMOS; DUCHON, 2000).

Tão necessária quanto os estudos acerca do jovem trabalhador e das práticas de espiritualidade é a pesquisa sobre o valor organizacional referente ao bem-estar do trabalhador, visto que ele influencia no comportamento do funcionário, impactando na execução das tarefas. Dito isso, objetiva-se com esse trabalho verificar as relações entre as práticas de espiritualidade e o valor organizacional - bem-estar, a partir da percepção de jovens trabalhadores, questionando sobre quais práticas de espiritualidade contribuem para a consecução do bem-estar destes?

Com efeito, este trabalho se encontra estruturado, além dessa peça introdutória, em mais cinco seções que são: a fundamentação teórica, abrangendo temas sobre o trabalho rotineiro, a espiritualidade e os valores organizacionais. Posteriormente, são apresentadas a metodologia, os resultados, a conclusão e as referências. 


\section{Fundamentação teórica}

Seção destinada a apresentar um passeio sobre aspectos, que indicam a necessidade da espiritualidade no âmbito organizacional.

\subsection{Trabalho: rotinização e significâncias}

O trabalho é visto por alguns autores como um instrumento de motivação humana que pode implicar em satisfação e produtividade para os que o exercem. Assim, o trabalho assume um papel de grande relevância para os trabalhadores, significando: a) a possibilidade de estabelecimento de vínculos com outras pessoas; b) um objetivo de vida; c) uma ocupação; e d) um artifício para evitar o tédio. Por conta disso, o trabalho passou a representar mais que uma relação remuneratória, constitui-se em fator de dignidade humana (PAUCHANT, 2000; MORIN, 2001; FRY, 2003, DEJOURS, 2004).

Reconhece-se que o trabalho acompanhou o processo de evolução social, uma vez que assumiu variadas formatações, ao longo dos tempos, representando: a) sobrevivência, b) distinção entre as classes sociais (braçal ou intelectual);c) castigo dos Deuses, d) ascetismo; e e) "força de trabalho". Sendo essa última considerada como mercadoria e transformada, a fim de aumentar a produtividade e proporcionar maiores lucros para as organizações (FARIAS; SCHMITT, 2004; ORNELLAS; MONTEIRO, 2006; RAMOS, 2008).

Como mercadoria, o trabalho foi cientificado por Taylor através do planejamento e da execução das tarefas, o que resultou em outros estudos quantitativos, como: a) os gráficos de controle de produção do trabalho (Gantt); b) a régua de cálculo para fadiga do trabalhador (Barth); c) os processos de cronometragem do trabalho (Thompson); d) o rendimento do trabalho (Emerson); e) a cientificação dos estudos dos movimentos (Gilbreths), dentre outros (RAMOS, 2008). Essa racionalização e controle exacerbados do trabalho resultaram em condições degradantes para os trabalhadores, atenuando conflitos entre empregados e empregadores, além de dividir opiniões acerca dos benefícios e malefícios do trabalho rotineiro e seriado (ORNELLAS; MONTEIRO, 2006; SENNETT, 2009).

Para aqueles que defendiam o trabalho rotineiro, tinham no mesmo reflexo da fraternidade, serenidade e da condição necessária para a aprendizagem, enquanto que os opositores consideravam este tipo de trabalho superficial e capaz de causar embrutecimento, estupidez, ignorância e "morte espiritual" no trabalhador. Para comprovar os malefícios do trabalho rotineiro, Elton Mayo experimenta fornecer tratamento humano aos trabalhadores e detecta aumento na produtividade (SENNET, 2009), uma vez que seu experimento buscava frear a racionalidade extrema aplicada às tarefas, alertando os patrões da necessidade de valorizar a subjetividade do trabalhador, porém a subjetividade continuou negligenciada pelas organizações.

\subsection{Subjetividade nas organizações}

A miopia em torno das dimensões do trabalhador, tão presente na era industrial, tornase obsoleta nas organizações contemporâneas, pois é necessário enxergar o indivíduo além das suas potencialidades racionais, considerando-o como um ser de 
múltiplas dimensões, respeitando-as, inclusive aquela que referencia o seu desenvolvimento interior - a espiritualidade. Investir em tecnologia é relevante, contudo, deve também haver investimentos nos valores humanos, que perpassam os ambientes laborais, a fim de evitar que a subjetividade seja expulsa, uma vez que são a emoção e a criatividade as responsáveis por diferenciar o homem da máquina (CHANLAT, 1996; DE MASI, 2001).

Dito isso, sacrificar a subjetividade em prol da maior rentabilidade e competitividade no meio corporativo, através do controle exacerbado de fatores objetivos (salários, manuais de comportamento, etc.) e subjetivos (necessidades relativas ao pertencimento; filiação; reconhecimento; carência afetiva; e realização do indivíduo) dos indivíduos, a fim de atenderem às necessidades organizacionais (DEJOURS, 2004; FARIA; SCHMITT, 2004), pode retirar da tarefa a espontaneidade; a criatividade; e a inovação, aspectos capazes de diferenciar uma corporação da outra (REGATIERI et al.,2010). Portanto, o respeito ao indivíduo na sua condição humana e subjetiva no trabalho pode contribuir para que a espiritualidade adentre a esses espaços, melhorando as condições laborais.

\subsection{Espiritualidade no mundo corporativo}

Acreditava-se, até a década de 1990, que a inteligência respondia apenas pelo campo da razão, mas Daniel Goleman revoluciona ao afirmar que o ser humano também é dotado de inteligência subjetiva que advém da emoção, acrescentando ainda que, essa inteligência é capaz de impactar diretamente o intelecto, afetando os pensamentos e as ações. Mais tarde, surge outra inteligência subjetiva - a espiritual, considerada como basilar para as demais inteligências do indivíduo (ZOHAR, MARSHAL, 2001). A partir de então, a espiritualidade passa a ser discutida.

Há uma diversidade de entendimento acerca da espiritualidade, podendo representar a base da civilização e o mais alto grau de enraizamento do indivíduo (WEIL, 1949); como a possibilidade de ser fator de harmonização entre natureza e espírito (MITROF, 2000); ou, ainda, algo capaz de responder às necessidades do indivíduo relativas à: a) significado; b) integração; e c) transcendência (PAUCHANT, 2000).

Nas organizações, a espiritualidade se apresenta como fator necessário para dar significado ao trabalho, ao reconhecer a vida interior dos trabalhadores e alimentar suas necessidades quanto ao pertencimento e afiliação (LEFEBVRE, 2000; ASHMOS; DUCHON, 2000), além de estar inserida na cultura organizacional, a partir da estruturação de valores, conectando as pessoas (GIACALONE; JURKIEWICZ, apud JURKIEWICZ; GIACALONE, 2003; REGO; SOUTO; CUNHA, 2005).

Não se deve confundir a espiritualidade com religião, pois estas não carregam o mesmo significado. A espiritualidade não visa converter as pessoas, mas permitir que experimentem a sensação de liberdade e alimentem a alma no sentido de significar o trabalho, diferentemente da religião em que a liberdade é confrontada com a burocracia e a formalidade. Portanto, igualar a espiritualidade com a religião é uma forma de discriminar a espiritualidade como ciência, uma vez que a religião e a ciência 
enfrentaram e enfrentam divergências teóricas (MITROFF, 2000; LEFEBVRE, 2000; SOUTO; REGO, 2006; FLINK et al.,2011).

A espiritualidade se baseia em cinco dimensões: a) Sentido de comunidade na equipe: designa a interação entre pessoas e a necessidade da vida em comunidade; b) Alinhamento do indivíduo com os valores da organização: representa "compatibilidade dos valores e da vida interior do indivíduo com os valores da organização"; c) Sentido de préstimo à comunidade (trabalho com significado): resulta no profundo senso de significado e propósito em seu trabalho, implicando em importantes valores de vida do indivíduo, representando utilidade para a comunidade; d) Alegria no trabalho: relaciona-se à satisfação e ao prazer no trabalho; e) Oportunidades para a vida interior: representa o respeito, da organização quanto à vida interior do indivíduo, seus valores espirituais (REGO; CUNHA; SOUTO, 2005; ASHMOS; DUCHON, 2000; MILLIMAN; CZPALEWISK; FERGUSON, 2003).

Estudos apontam que a implantação da espiritualidade nas organizações gera benefícios como: melhorias na saúde do trabalhador; redução do turnover e absenteísmo; aumento do comprometimento; e possível incremento na produtividade, devido à satisfação e realização das tarefas (PANAHI, 2012; VERGARA; MOURA, 2012; AJALA, 2013). Mesmo com essas afirmações, a resistência em inserir práticas de espiritualidade nas corporações, ainda persiste e talvez seja explicada devido à impregnação da racionalidade, que ofusca a visão para outras práticas senão as quantitativas (JURKIEWICZ; GIACALONE, 2003; REGO; CUNHA; SOUTO, 2005; VASCONCELOS, 2015).

\subsubsection{Práticas de espiritualidade organizacional}

Muitos são os desafios que precisam ser superados, a fim de fazer da espiritualidade uma prática factível no âmbito organizacional, pois há gerentes entusiasmados em relação ao assunto, mas temerosos quanto a sua implantação devido fatores como: preconceito em relação ao tema; medo da perseguição; ausência de modelos e ferramentas gerenciais; dificuldade de conciliação entre os interesses econômicos e os princípios da espiritualidade; e a possibilidade de manipulação dos funcionários em prol dos interesses materialistas das organizações (FRESHMAN, 1999; MITROFF, 2000; PAUCHANT, 2000).

Para tentar minimizar os entraves da implantação da espiritualidade no meio corporativo sugere-se que ela ocorra, de forma autêntica, buscando melhorias no âmbito geral e não apenas com o intento de auferir maiores lucros, pois as inserções dessas práticas devem visar à valorização do trabalhador, que ao se sentir valorizado de forma genuína, esforçar-se-á para tornar o clima organizacional harmonioso, alegre e cooperativo (MILLIMAN, CZAPLEWISK, FERGUSON, 2003; SOUTO; REGO, 2006).

Para Bezerra e Oliveira (2007), assim como Farias, Melo e Lima (2017), as práticas de espiritualidade são descritas como:

a) Exercício da espiritualidade: trata-se da difusão dos conceitos da espiritualidade, através da comunicação interna e da promoção de palestras 
e cursos: do incentivo à meditação; da promoção da qualidade de vida e dos valores universais; da abertura de diálogos, acatando sugestões;

b) Valorização do funcionário: respeitar o indivíduo como pessoa; evitar a valorização excessiva das metas; fornecer tratamento digno aos funcionários; respeitar as necessidades emocionais; promover ações de reconhecimento do trabalhador; investir na motivação dos trabalhadores; valorizar o indivíduo pelos seus valores morais e não pelas metas alcançadas; reduzir as pressões para o alcance das metas; investir no desenvolvimento do trabalhador;

c) Diminuição da competição interna: é o ato de desestimular a competição entre os colegas; estimular o companheirismo, respeito e interação entre os trabalhadores; treinar para evitar preconceitos e desrespeitos no ambiente organizacional; induzir momentos de integração;

d) Diminuição da carga de trabalho: é a redução do estresse e cansaço; destinação de tempo para ações comunitárias e práticas da espiritualidade; diminuir a carga de trabalho exaustiva; permitir a meditação; oferecer espaço para relaxamento após as refeições;

Os aspectos positivos da implantação da espiritualidade no ambiente laboral versam no sentido de fatores como: comprometimento; aumento do moral; redução do estresse; aumento do desempenho; aumento da lealdade e eficácia. Já os negativos são descritos como: a) o perigo do proselitismo; b) a questão da compatibilidade de crenças ou interesses; c) o risco de a espiritualidade nas organizações se tornar mais um modismo gerencial e ser utilizada como ferramenta de manipulação dos trabalhadores, e d) a falta de legitimidade da espiritualidade no trabalho em teoria, pesquisa e prática (KARAKAS, 2010).

Há cientistas que consideram utopia estudar a espiritualidade, quando as taxas de desemprego apresentam níveis elevados, por outro lado, o próprio desemprego, por vezes, pode se apresentar como uma das consequências da falta de espiritualidade nas organizações, bem como da precariedade das condições de trabalho (SILVA, 2008; VERGARA; MOURA, 2012), haja vista que a prática da espiritualidade versa no sentido de promover o bem-estar do conjunto e não apenas do indivíduo isoladamente.

Os executivos mais motivados e apaixonados são os mais propensos a ver na espiritualidade um caminho para tornar a organização em espaços harmoniosos e repletos de alegria (KAUANUI et al., 2010; AJALA, 2013). Além disso, é necessário fazer um investimento sério em programas de desenvolvimento dos recursos humanos com ênfase nos valores, que permeiam a organização (NEIL, 2013), pois não há como se falar em implantação de práticas de espiritualidade sem pensar em mudanças nos valores organizacionais. 


\subsection{Valores organizacionais}

O valor é o parâmetro utilizado pelas pessoas para adotar um caminho, aferir acerca de diversos fatores. Nas organizações, o valor indica as percepções dos trabalhadores acerca do ambiente laboral, sendo oriundo da cultura corporativa e designador da identidade organizacional (SCHWARTZ, 1994; FLEURY, 1996).

A escolha de algo dentre outros implica atribuir maior valor para a opção feita. Além disso, o valor também pode nortear o comportamento dos indivíduos, sendo ainda, crenças; construção motivacional; metas abstratas; normas e critérios que hierarquizam as prioridades, além de referenciar os requisitos universais relativos às necessidades biológicas; de interação social e de bem-estar em comunidade (TAMAYO; SCHWARTZ, 1993,1994).

A academia tem desenvolvido interesse no estudo dos valores, haja vista a quantidade de publicações durante o período de 1992 a 2014, correspondendo a 263 artigos (SCIELO), e estes obedecem uma curva crescente (gráfico 1).

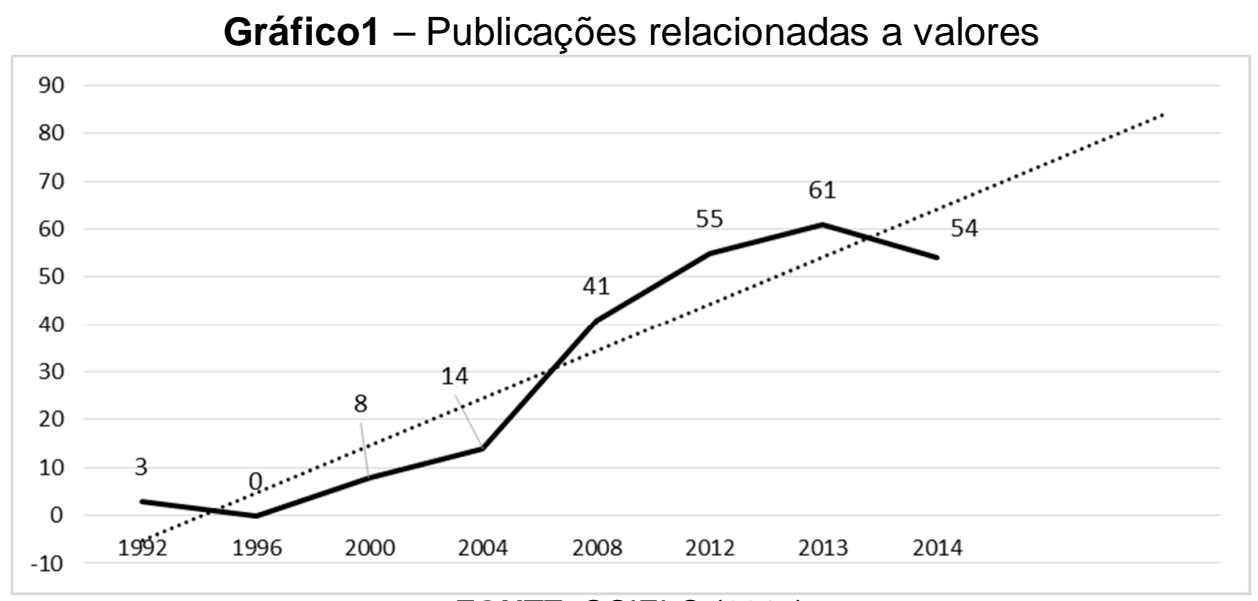

FONTE: SCIELO (2015)

Os primeiros valores a serem pesquisados foram os valores individuais, depois a atenção foi voltada para os valores organizacionais, a demora em se pesquisar os últimos pode ter ocorrido pela dificuldade em mensurá-los, uma vez que estes descrevem a percepção do trabalhador acerca da corporação em que está inserido. $\mathrm{O}$ valor organizacional conduz os funcionários às metas corporativas transmitindo princípios e crenças, a fim de atender aos interesses individuais, coletivos ou mistos direcionando o comportamento de todos através da criação de modelos mentais (TAMAYO; GONDIM, 1996; TAMAYO, 1998). Esses modelos mentais podem gerar sofrimento ou prazer no trabalhador, dependendo da rigidez ou flexibilidade das normas institucionais, e da participação dos funcionários nas decisões (TAMAYO; MENDES; PAZ, 2000).

Os valores organizacionais se originam das pessoas, a partir de necessidades biológicas; de sobrevivência; e de bem-estar dos indivíduos e das organizações (TAMAYO; GONDIM, 1996; TAMAYO; MENDES; PAZ, 2000; TAMAYO, 2002). Dito 
isso, acredita-se que trabalhadores felizes contribuem mais facilmente para a consecução das metas organizacionais (TAMAYO et al.,2000).

Os valores organizacionais diferem dos valores individuais a partir de que os primeiros versam no sentido coletivo, enquanto que os últimos correspondem aos objetivos pessoais e servem como princípios na vida de cada pessoa (TAMAYO; GONDIM, 1996; TAMAYO apud MENDES; TAMAYO, 2001; TAMAYO, 2007; MAURINO, DOMENICO, 2012). Logo, para medir os valores organizacionais, Álvaro Tamayo e colaboradores criaram três escalas: a) Escala de Valores Organizacionais - EVO (1996); b) Inventário de Valores Organizacionais - IVO (2000); e c) Inventário de Perfis de Valores Organizacionais - IPVO (2004) (MELO; DOMENICO,2012). Sendo este último o objeto de estudo dessa pesquisa, devido trazer em seu bojo o fator bemestar dos trabalhadores.

O IPVO surgiu do entendimento de que os valores organizacionais possuíam uma similaridade motivacional com os valores pessoais, constatando tal semelhança a partir dos aspectos relacionados com a origem, a função e os componentes motivacionais. Logo, para a criação desse instrumento, os autores se basearam na teoria dos valores humanos, e na observação de dados reais de organizações alcançando oito fatores: realização; conformidade, domínio, bem-estar; tradição; prestígio organizacional; autonomia; e preocupação com a coletividade (OLIVEIRA; TAMAYO, 2004). O quadro 1 explana a correspondência entre os fatores do IPVO com os tipos motivacionais de valores, bem como as metas a serem alcançadas, quando se investe nos valores citados.

Quadro 1 - Inventário de Perfis dos Valores Organizacionais (IPVO)

\begin{tabular}{|c|c|c|}
\hline Fatores & Valores & O que mensura? \\
\hline Realização & Realização & $\begin{array}{l}\text { Competência da organização e dos } \\
\text { trabalhadores para alcançar sucesso }\end{array}$ \\
\hline Conformidade & Conformidade & $\begin{array}{l}\text { Respeito às regras e aos modelos de } \\
\text { comportamentos }\end{array}$ \\
\hline Domínio & Poder & Obter lucro, ser competitiva e dominar mercado \\
\hline Bem-estar & Hedonismo & $\begin{array}{l}\text { Promoção do bem-estar e qualidade de vida } \\
\text { dos trabalhadores }\end{array}$ \\
\hline Tradição & $\begin{array}{l}\text { Conservadoris } \\
\text { mo }\end{array}$ & Preservação e respeito aos costumes \\
\hline $\begin{array}{r}\text { Prestígio } \\
\text { Organizacional }\end{array}$ & Poder & $\begin{array}{l}\text { Capacidade de Ser conhecida, admirada por } \\
\text { todos }\end{array}$ \\
\hline Autonomia & $\begin{array}{l}\text { Autodeterminaç } \\
\text { ão e } \\
\text { estimulação }\end{array}$ & $\begin{array}{l}\text { Capacidade de estimular os trabalhadores na } \\
\text { direção da criatividade e inovação }\end{array}$ \\
\hline $\begin{array}{r}\text { Preocupação } \\
\text { com a } \\
\text { coletividade }\end{array}$ & $\begin{array}{l}\text { Benevolência } \\
\text { Universalismo }\end{array}$ & $\begin{array}{l}\text { Capacidade de promover: justiça, igualdade, } \\
\text { tolerância, sinceridade e honestidade em seu } \\
\text { ambiente. }\end{array}$ \\
\hline
\end{tabular}

FONTE: Oliveira e Tamayo (2004) 
O recorte deste estudo se debruçou no valor bem-estar, desta forma, inquiriu-se estudar as seis questões do IPVO relacionadas ao mesmo e que abordam situações quanto à preocupação da organização para com seus empregados, envolvendo: qualidade de vida; possibilidades de diversão, premiação e prazer; oferta de ajuda; e manutenção de clubes de lazer.

\subsubsection{Bem-estar dos trabalhadores}

Para Dutra (2001, apud CANOVA, PORTO, 2010), os estudos relacionados ao bemestar se tornaram aparentes, a partir do segundo período do século XIX, por intermédio do fisiologista francês Charles Bernard, que defendia que a manutenção do bem-estar dever-se-ia respeitar um dos aspectos principais, que seria a "habilidade do organismo para manter a constância do seu ambiente interno, mesmo com as mudanças que ocorrem externamente" (p.7).

O trabalhador percebe o bem-estar ao passo que a organização demonstra preocupação nesse sentido. Assim, a percepção de bem-estar obtida pelos trabalhadores está atrelada à qualidade de vida no ambiente laboral, bem como a possibilidade de abertura e inovação, sendo que a base teórica do bem-estar são os "valores do tipo motivacional Hedonismo" (OLIVEIRA; TAMAYO, 2004).

As definições acerca do bem-estar não são consensuais entre os autores, em virtude disso, contudo, sinonimizam-se com a felicidade (PASCHOAL; TAMAYO, 2008). Van Horn et al. (2004, apud PASCHOAL; TAMAYO, 2008) entendem que o bem-estar no trabalho é a avaliação positiva das características do trabalho, que inclui afeição, motivação e comportamentos cognitivos e psicossomáticos. Para Waterman (2006, apud SOBRINHO, PORTO, 2012), o bem-estar é "um estado afetivo" e ocorre quando os afetos positivos se sobrepõem aos aspectos negativos.

Outra definição aponta que "O bem-estar é mais elevado quanto mais frequente e intensas forem as emoções positivas e quanto mais elas prevalecerem sobre o afeto negativo do trabalhador" (PASCHOAL, TORRES, PORTO, 2010). Logo, para este estudo se considera como bem-estar a sobreposição de fatores agradáveis sobre os fatores desagradáveis, que desencadeiam uma sensação de prazer para o trabalhador ao realizar suas tarefas laborais, levando em consideração questões quanto à qualidade de vida; possibilidades de diversão, premiação e prazer; oferta de ajuda; e manutenção de clubes de lazer (Oliveira; Tamayo, 2004).

A sensação de bem-estar que pode acometer os trabalhadores pode ser excluída ao passo que esses são submetidos à realização de "atividades burocráticas, de natureza inferior à sua capacidade e habilidade, com tempo insuficiente, falta de comunicação da gestão superior e falta de treinamento adequado". Assim, um estudo realizado com professores constatou ser, dentre outros valores, o bem-estar como preditor do estresse ocupacional (CANOVA; PORTO, 2010, p.26).

Avaliando a presença da espiritualidade como promotora de bem-estar para os trabalhadores no cenário organizacional, Panahi (2012) considera a espiritualidade no ambiente de trabalho como um instrumento promotor de benefícios de ordem pessoal 
e organizacional, haja vista os registros de melhorias na saúde e no bem-estar dos indivíduos, além do aumento do comprometimento do empregado, redução de tournover, menor índice de absenteísmo e maior produtividade.

Nesse sentido, Ajala (2013) afirma que "o bem-estar dos colaboradores é garantido com a introdução da espiritualidade no trabalho", ressaltando que essa garantia proporciona que o trabalhador desenvolva suas atividades com um espírito de comprometimento, encontrando significado, finalidade e satisfação no local de trabalho de modo que sejam reduzidos os níveis de estresse, conflito e absenteísmo. Não obstante, complementa que a espiritualidade no ambiente de trabalho tem "o potencial de contribuir principalmente para o bem-estar do ser humano, nutrindo suas conexões e aumentando a sensação de desenvolvimento comunitário no ambiente de trabalho"

\section{Metodologia}

A metodologia aplicada é de cunho quantitativo e descritivo, uma vez que esta pesquisa foi realizada através do levantamento de dados, a partir de questionário estruturado, composto de 17 questões sociodemográficas, além de 70 questões no formato da escala Likert de 6 pontos, relacionadas aos valores e espiritualidade organizacionais, sendo que a escala relacionada aos valores listou todos os fatores do IPVO, sendo que para este estudo em específico, foram avaliadas apenas as variáveis relativas ao bem-estar e as práticas de espiritualidade, por ser este o foco do estudo. A aplicação do questionário ocorreu por intermédio de links disponibilizados através de e-mails para as instituições participantes da pesquisa, que continham programas de aprendizagem com jovens.

O universo da pesquisa abrangeu jovens trabalhadores brasileiros pertencentes a programas de aprendizagem, com idade entre 18 e 24 anos, que apresentassem alguma experiência laboral. Foram obtidos 406 questionários válidos e em torno de $99 \%$ dos respondentes da pesquisa foram oriundos das instituições: SENAC (BA), ISBET (DF) e ISBET (BA).

O esquema teórico da pesquisa buscou verificar as relações existentes entre as práticas de espiritualidade e o valor organizacional - bem-estar, assim, constituiu-se na figura 1. 
Figura 1- Relações entre práticas de espiritualidade e bem-estar

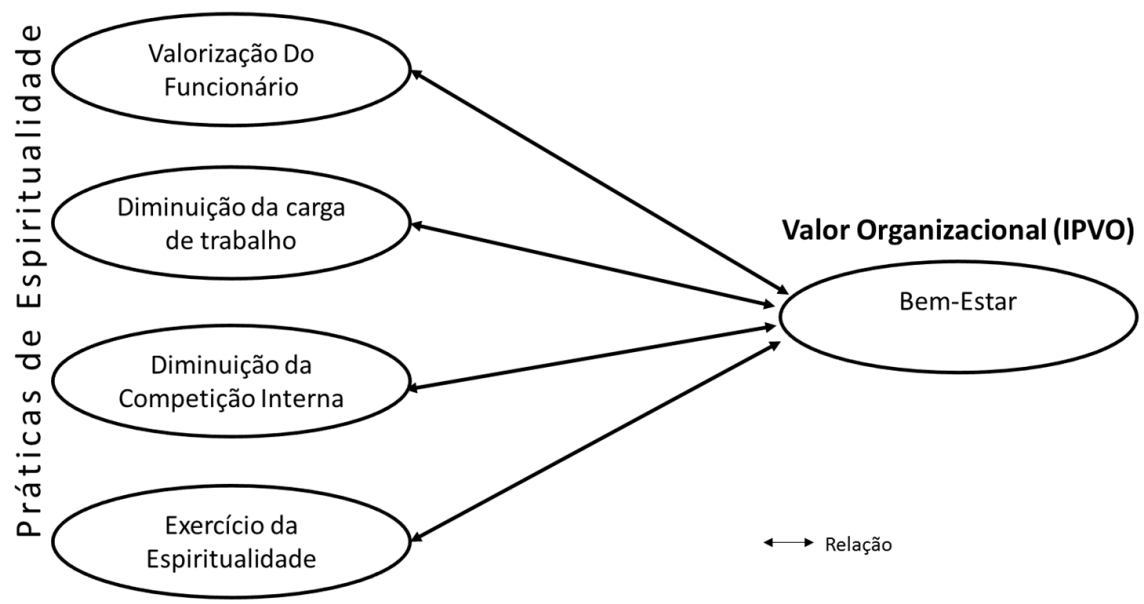

FONTE: Dados da pesquisa (2016)

O software Statistical Package for the Social Sciences - SPSS Statistics 23.0 foi utilizado para a tabulação, análise e saída dos dados. A análise das relações entre as variáveis do estudo foi obtida através da matriz de correlações de Spearman, utilizando-se como parâmetro a seguinte condição: se rho $\geq 0,7$ implica forte relação de magnitude; se $0,4<$ rho $<0,7$, implica moderada relação de magnitude; e se rho < 0,4 implica fraca relação de magnitude. A escolha pelo coeficiente de Spearman ocorreu por este ser o mais adequado para análise de escalas ordinais.

\section{Resultados}

Da análise sociodemográfica se identificou que o gênero feminino foi preponderante entre os respondentes, correspondendo a $67 \%$ do total, contra $33 \%$ referente ao gênero masculino. A maioria dos pesquisados (65,5\%) tinha entre 18 a 20 anos, sendo que destes, $70 \%$ foram mulheres. $90 \%$ dos jovens se declararam solteiros, e $70 \%$ dos pesquisados se autodeclararam negros ou pardos. Aproximadamente $60 \%$ dos jovens pesquisados já havia concluído o nível médio.

$\mathrm{Na}$ análise descritiva dos dados se percebeu que a maioria dos jovens trabalhadores considera que a sua organização é parecida ou muito parecida com a organização, que investe na promoção do bem-estar dos seus funcionários. Tal fato pode ser evidenciado, a partir da tabela 1, que demonstra maior concentração de respostas nas duas últimas opções (é parecida / muito parecida). 
Tabela 1 -Frequências: Bem-estar (\%)

\begin{tabular}{|c|c|c|c|c|c|c|}
\hline & $\begin{array}{c}\text { Não se } \\
\text { parece } \\
\text { nada }\end{array}$ & $\begin{array}{l}\text { Não se } \\
\text { parece }\end{array}$ & $\begin{array}{l}\text { Pouco } \\
\text { parecida }\end{array}$ & $\begin{array}{c}\text { Mais ou } \\
\text { menos } \\
\text { parecida }\end{array}$ & $\begin{array}{c}\text { É } \\
\text { parecida }\end{array}$ & $\begin{array}{c}\text { Muito } \\
\text { parecida }\end{array}$ \\
\hline $\begin{array}{l}\text { É muito importante para esta } \\
\text { organização ajudar seus } \\
\text { empregados. Ela deseja cuidar } \\
\text { do bem-estar deles. }\end{array}$ & 5,4 & 10,1 & 10,6 & 21,9 & 25,4 & 26,6 \\
\hline $\begin{array}{l}\text { Esta organização oferece } \\
\text { oportunidades de diversão aos } \\
\text { empregados. Ela acha } \\
\text { importante que eles tenham } \\
\text { prazer no trabalho. }\end{array}$ & 14,8 & 9,6 & 15,5 & 19,0 & 21,7 & 19,5 \\
\hline $\begin{array}{llr}\text { Nesta organização, } & \text { os } \\
\text { empregados são premiados. A } \\
\text { satisfação deles com a } \\
\text { organização é uma meta } \\
\text { importante. }\end{array}$ & 11,3 & 11,1 & 10,3 & 21,4 & 21,4 & 24,4 \\
\hline 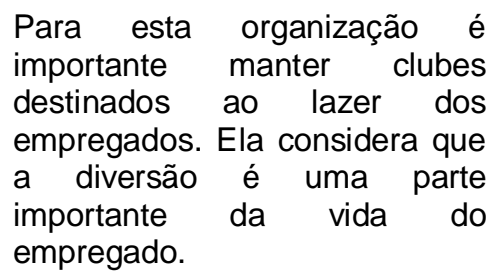 & 24,4 & 14,5 & 9,9 & 20,0 & 14,5 & 16,7 \\
\hline $\begin{array}{l}\text { Esta organização se preocupa } \\
\text { com a qualidade de vida dos } \\
\text { empregados. Ela realiza projetos } \\
\text { sociais que contribuem para o } \\
\text { bem-estar deles. }\end{array}$ & 14,0 & 12,1 & 10,8 & 23,6 & 17,5 & 21,9 \\
\hline $\begin{array}{l}\text { Esta organização propõe } \\
\text { atividades que dão prazer ao } \\
\text { empregado. } \mathrm{Na} \text { visão dela, é } \\
\text { importante o empregado se } \\
\text { sentir satisfeito consigo mesmo. }\end{array}$ & 13,5 & 11,1 & 12,1 & 21,7 & 20,0 & 21,7 \\
\hline
\end{tabular}

FONTE: dados da pesquisa 2016

Ao correlacionar as práticas de espiritualidade com o valor organizacional relativo ao bem-estar, conforme aponta a tabela 2 , observa-se que as relações estabelecidas entre as práticas de espiritualidade e o valor organizacional relacionado ao bem-estar apresentaram forte relação de magnitude entre as variáveis: diminuição de carga de trabalho versus bem-estar; exercício da espiritualidade versus bem-estar; valorização do funcionário versus bem-estar, enquanto que a relação entre variáveis diminuição da competição interna versus bem-estar apresentou moderada relação de magnitude. 
Tabela 2- Relações entre Práticas de Espiritualidade e Valores Organizacionais

\begin{tabular}{c|r|r|r|r|r}
\hline \multicolumn{2}{c|}{} & \multicolumn{4}{|c}{ Práticas de Espiritualidade } \\
\cline { 2 - 6 } \multicolumn{2}{c|}{} & $\begin{array}{c}\text { Diminuir Carga } \\
\text { de Trabalho }\end{array}$ & $\begin{array}{c}\text { Exercício da } \\
\text { Espiritualidade }\end{array}$ & $\begin{array}{c}\text { Valorização } \\
\text { do } \\
\text { Funcionário }\end{array}$ & $\begin{array}{c}\text { Diminuição da } \\
\text { competição } \\
\text { interna }\end{array}$ \\
\hline Valor & Bem- &, $708^{* *}$ &, $777^{\star *}$ &, $738^{\star *}$ &, $613^{* *}$ \\
Organizacional & Estar &, 000 &, 000 &, 000 &, 000 \\
\hline
\end{tabular}

**. A correlação é significativa no nível 0,01 (bilateral).

FONTE: dados da pesquisa 2016

A forte relação de magnitude observada entre as variáveis da prática de espiritualidade e o bem-estar apresentada, pela matriz de correlações, pode indicar que essas variáveis impactam umas nas outras. O que implica dizer que, possivelmente, quando a organização investe em práticas de espiritualidade, como diminuição da carga de trabalho; exercício da espiritualidade e valorização do funcionário, o jovem trabalhador percebe a preocupação da organização para com o seu bem-estar e se sente satisfeito nessa relação. O esquema teórico, representado pela figura 2, reforça o entendimento acerca da força das relações entre as práticas de espiritualidade e valores organizacionais, apontando como única relação moderada, a estabelecida entre a diminuição da competição interna e o bem-estar.

Figura 2- Relações entre práticas de espiritualidade e bem-estar

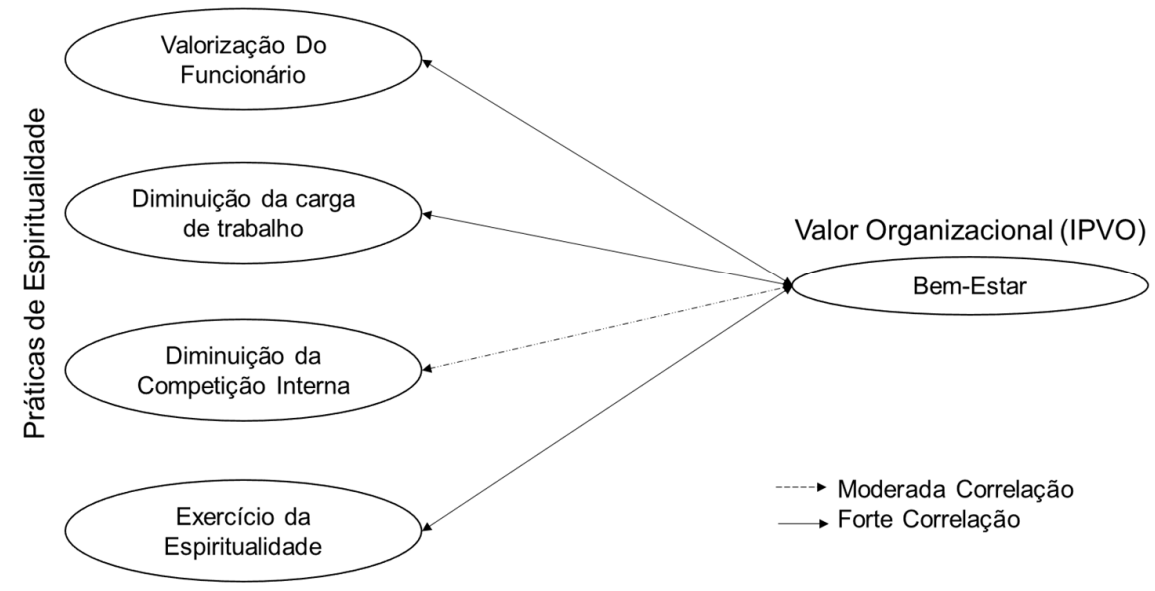

FONTE: Dados da pesquisa (2016)

A partir do gráfico de dispersão, representado pela figura 3, nota-se a forte associação entre as variáveis "diminuição da carga de trabalho" e "bem-estar", devido à concentração de dados demonstrar um comportamento linear. Tal associação pode ser explicada em virtude de que, ao investir em ações que visem à diminuição da carga de trabalho, como redução do estresse e do cansaço nos ambientes laborais, de modo que o jovem trabalhador destine um tempo para o relaxamento, meditação e ações comunitárias, a organização poderá promover a sensação de bem-estar em 
seus trabalhadores, além da satisfação e da qualidade de vida, pois em virtude da linearidade entre as variáveis, acredita-se que quanto menor a carga de trabalho, maior será o bem-estar para os jovens trabalhadores, haja vista que o bem-estar está diretamente relacionado à qualidade de vida no trabalho (OLIVEIRA; TAMAYO, 2004).

Figura 3 - Diminuição da Carga de Trabalho X Bem-Estar

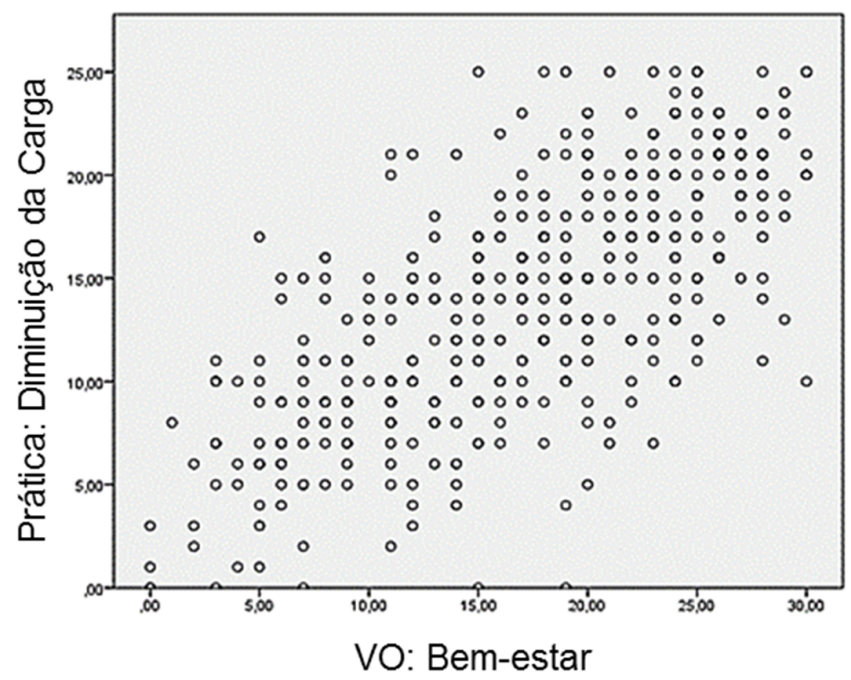

FONTE: dados da pesquisa 2016

A relação existente entre o "exercício da espiritualidade" e o "bem-estar" denota forte magnitude e é possível que este fato advenha do pressuposto de que, ao passo que a organização exercite ações de espiritualidade, no sentido de alinhar os valores dos indivíduos com os valores da organização visando estabelecer: a postura ética; a prática dos valores universais; a qualidade de vida; o incentivo à meditação; e a promoção de treinamentos e cursos para difundir os conceitos da espiritualidade, consequentemente, esta poderá proporcionar maior sensação de bem-estar aos jovens trabalhadores, pois de acordo com Ashmos e Duchon (2000), quando a espiritualidade é inserida no ambiente organizacional, os funcionários percebem que há uma real preocupação da organização para com o bem-estar dos seus funcionários (figura4). 
Figura 4 - Exercício da espiritualidade X Bem-Estar

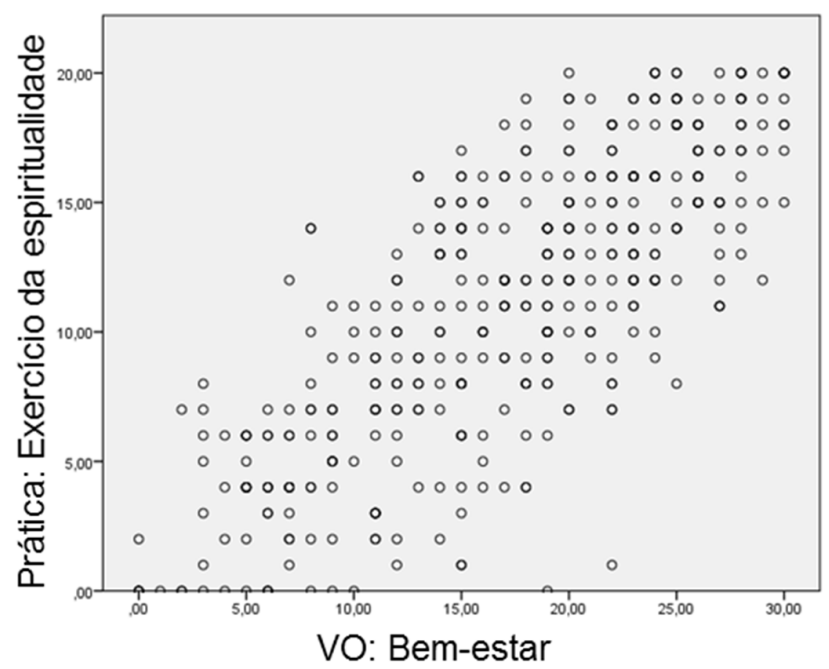

FONTE: dados da pesquisa 2016

No que tange a forte associação de magnitude entre "valorização do funcionário" e " bem-estar", é possível que essa percepção ocorra em virtude da percepção do jovem trabalhador apontar para direção de que se obtém o bem-estar no ambiente organizacional ao passo que a organização pratique a espiritualidade com o intuito de: respeitar as necessidades emocionais do trabalhador; valorizar o trabalhador tanto nas suas dimensões intelectuais quanto emocionais; investir na motivação dos trabalhadores; conceder tratamento digno a todos; reduzir as pressões para o alcance das metas; reconhecer os esforços dos trabalhadores através do feedback. Assim, Ajala (2013) afirma que se a organização entende que o trabalhador não leva para o ambiente de trabalho apenas seu corpo e mente, mas também seu coração, alma e espírito, ela pode ampliar a satisfação e comprometimento dos seus funcionários melhorando o bem-estar de todos (figura 5).

Figura 5- Valorização do Funcionário X Bem-Estar

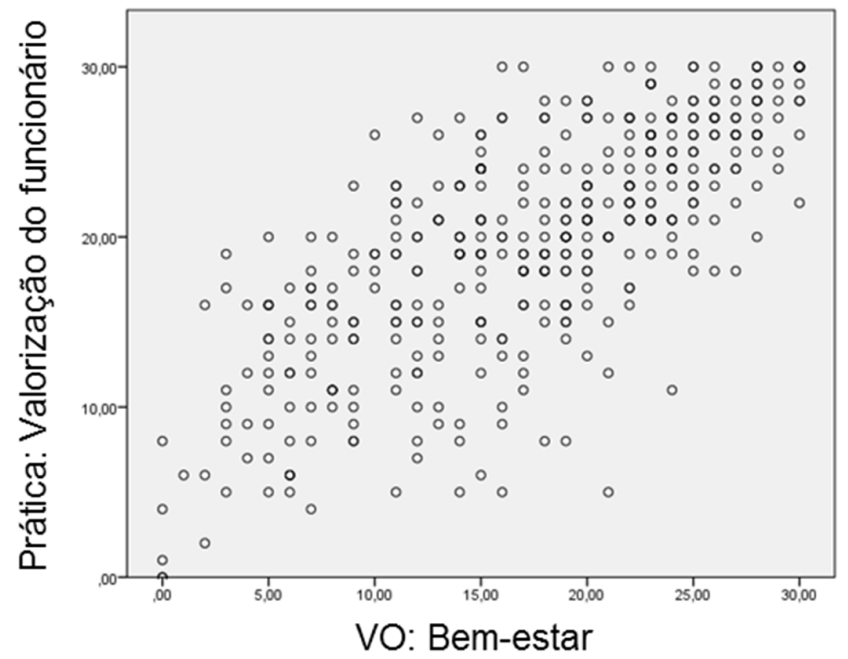

FONTE: dados da pesquisa 2016 
Ao analisar a correlação existente entre as variáveis "diminuição da competição interna" e o "bem-estar", identificou-se correlação com moderada magnitude, indicando maior dispersão dos dados, o que pode implicar que, para os jovens trabalhadores, a diminuição da competição interna representada pelo estímulo do companheirismo, respeito e interação entre os trabalhadores, bem como 0 treinamento para evitar preconceitos e desrespeitos no ambiente organizacional, integrando os indivíduos, a fim de que eles compartilhem uma vida em comunidade afeta tanto ao bem-estar de forma moderada (figura 6). É possível que este dado tenha apresentado essa configuração em virtude de que o trabalhador pode experimentar a sensação de prazer, quando se debruça em trabalhos desafiadores (VERGARA; MOURA, 2012).

Figura 6- Diminuição da competição interna X Bem-Estar

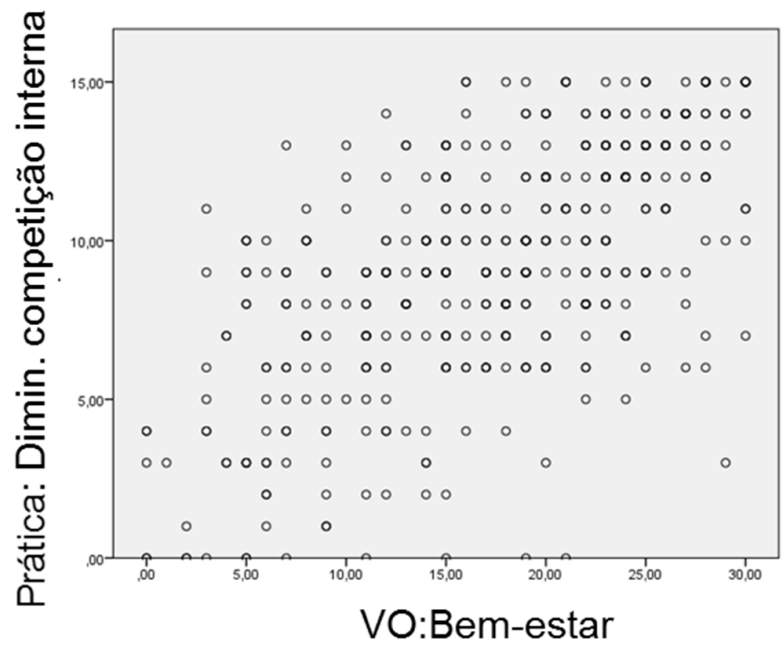

FONTE: dados da pesquisa 2016

Portanto, para o jovem trabalhador, a percepção acerca do bem-estar pode vir através da adoção de práticas por parte da organização, relacionadas à espiritualidade no que tange a: "diminuição da carga de trabalho"; "valorização do funcionário" e "exercício da espiritualidade".

\section{Considerações finais}

Este estudo buscou verificar as relações entre as práticas de espiritualidade e o valor organizacional - bem-estar, a partir da percepção de jovens trabalhadores. Afirma-se que este objetivo foi alcançado, encontrando, inclusive, relação entre as variáveis do estudo. Dessa forma, os dados demonstraram que, quando a organização adota como prática a "diminuição da carga de trabalho", investindo na redução do estresse, na disponibilização de tempo para ações comunitárias, relaxamento e meditação, os indivíduos tendem a experimentar a sensação de bem-estar em seus ambientes laborais.

A organização também proporciona o bem-estar, acumulado ao estímulo à criatividade e à inovação para os funcionários, quando adota práticas concernentes 
ao "exercício da espiritualidade", a partir da difusão e da prática dos conceitos da espiritualidade, por intermédio de palestras e cursos voltados para: a) trabalho em equipe; b) alinhamento dos valores organizacionais e individuais; c) alegria no trabalho; d) desenvolvimento da pessoa como ser humano e, e) ações comunitárias, além de proporcionar ao trabalhador qualidade de vida e promoção dos valores universais.

Por fim, ao praticar ações no sentido de "valorização do funcionário", concedendo a este: tratamento digno e respeitoso; reconhecimento de suas ações e emoções; investimento na sua motivação; e redução das pressões para o alcance das metas, observa-se que o funcionário tende a experimentar a sensação de promoção do bemestar.

A prática de espiritualidade, "diminuição da competição interna", representada por ações que envolvem a promoção do companheirismo entre os colegas e o desestímulo à competição, apresentou relação com menor intensidade que as demais práticas com os valores organizacionais relativos ao bem-estar e estímulo à inovação e à criatividade (autonomia).

As limitações apresentadas neste estudo se referem aos termos utilizados na escala de valores organizacionais, o que pode em alguns momentos não ter ficado claro 0 suficiente para o jovem, enviesando a pesquisa, mesmo que este tenha sido submetido ao pré-teste. A extensão do questionário também pode ser considerada como um fator limitador, uma vez que este ao abarcar todas as partes: sociodemográficas; valores organizacionais e espiritualidade somam 87 questões. Pode-se considerar, ainda, como fator limitador a falta de contribuição por parte das organizações, que negaram a pesquisa em seus ambientes e, portanto, impediram o desenvolvimento da ciência. Sugere-se, logo, que nas próximas pesquisas sejam envolvidos todos os agentes promotores do programa de aprendizagem: jovem, instituição mediadora e organizações, a fim de identificar se as percepções dos jovens coadunam com os valores, documentos e as práticas organizacionais.

\section{Referências}

ALMEIDA, F.J.R. de; SOBRAL, F.J.B. de A. O sistema de valores humanos de administradores Brasileiros: adaptação da escala PVQ para o estudo de valores no Brasil. RAM, Rev. Adm. Mackenzie, São Paulo, v.10, n. 3, p. 101-126, Jun. 2009

AJALA, E.M. The Impact of Workplace Spirituality and Employees' Wellbeing at the industrial Sectors: The Nigerian Experience. The African Symposium: An online Journal of the African Educational Research Network. Vol.13, No.2, 3-13. 2013

AKTOUF, O. A administração entre a tradição e a renovação. Organização, adaptação e revisão Tradução: Roberto Fachin e Tânia Fischer. São Paulo: Atlas, 2010.

ASHMOS, D.P.; DUCHON, D. Spirituality at work: A conceptualization and measure. Journal of Management Inquiry, v. 9, n. 2, p. 134-145, 2000. 
BEZERRA, M. de F. da N.; OLIVEIRA, L.M.B. de. Espiritualidade nas Organizações e Comprometimento Organizacional. Estudo de Caso com um Grupo de Líderes de Agências do Banco do Brasil na cidade de Recife. In: XXXI ENANPAD. Anais...,Rio de Janeiro: Anpad, 2007.

CHANLAT, J. F. Por uma Antropologia da condição humana nas organizações. In: Chanlat, Jean François (Coord.). 0 indivíduo na organização: dimensões esquecidas. Tradução Ofélia de Lanna Sette Tôrres. 3. ed. São Paulo: Atlas. v. I. 1996.

DANIEL, J.L. The effect of workplace spirituality on team effectiveness. Journal of Management Development, Vol. 29 Iss: 5, pp.442 - 456. 2010

DE MASI, D. O futuro do trabalho: fadiga e ócio na sociedade pós-industrial. Tradução de Yadyr A. Figueiredo. Rio de Janeiro: José Olympio. 2001

DEJOURS, C. Subjetividade, trabalho e ação. Revista Produção, São Paulo, v. 14, n. 3, p. 27-34, dez. 2004 Disponível em $<$ http://www.scielo.br/scielo.php?script=sci arttext\&pid=S0103 65132004000300004\&lng=en\&nrm=isso >. Acesso dez 2015. http://dx.doi.org/10.1590/S0103-65132004000300004.

FARIA, J.H.; SCHMITT, E.C. Indivíduo, Vínculo e Subjetividade: O Controle Social a Serviço das Organizações. EnEO, 3., Atibaia/SP. Anais... São Paulo, 6 a 8 de junho de 2004, pp. 01-16

FARIAS, F.G.; MELO, J.M.G.N.; LIMA, F.N. Concepções e práticas sobre espiritualidade nas organizações: a visão de acadêmicos, gestores e subordinados. Revista Foco, [S.I.], v.10, n.1, jan.2017. ISSN 1981-223X. Disponível em: http://www.novomilenio.br/periódicos/index.php/foco /article/view/322/200.Acesso em: 04 abr. 2017.

FLEURY, M.T.L. O Desvendar a Cultura de uma Organização: uma discussão metodológica. In: FLEURY, Maria Tereza Leme. FISCHER, Rosa Maria (orgs.). Cultura e Poder nas Organizações. São Paulo: Atlas. 2ed. 1996.p.15-27.

FLINK, R.J.S.; VERGILIO, M.E.; OLIVEIRA, M.D. de ; CORREA, M.S.; RODRIGUES S. Espiritualidade nas Organizações: os colaboradores estão envolvidos com isso? $\mathrm{E}$ as organizações? VIII Convibra Administração - Congresso Virtual Brasileiro de Administração. 2011. Anais.... Disponível em: www.convibra.com.br. Acesso em jun.2015

FRESHMAN, B. An exploratory analysis of definitions and applications of spirituality in the workplace. Journal of Organizational Change Management, 12(4), 318- 327, 1999.

FRY, L. W. Toward a theory of spiritual leadership. The Leadership Quarterly, v. 14, p. 693-727, 2003. 
GIACALONE, R.A.; JURKIEWICZ, C. L. Toward a science of workplace spirituality. In: GIACALONE R. A e. JURKIEWICZ C. L (Eds.), The Handbook of Workplace Spirituality and Organizational Performance. Armonk, NY: M. E. Sharpe, 2003

KARAKAS, F., Spirituality and Performance in Organizations: A Literature Review. Journal of Business Ethics, Vol. 94, No. 1, pp. 89-106, 2010.

KAUANUI, K.S. et al. Entrepreneurship and spirituality: a comparative analysis of entrepreneurs' motivation. Journal of Small Business \& Entrepreneurship, v. 23, p. 621-635, 2010.

LAZZARESCHI, N. Trabalho ou emprego? São Paulo: Paulus, 2007.

LEFEBVRE, S. La crise du croire em enterprise et la necessite d'um dialogue sur la signification du travail. In Pauchant, Thierry et associés : Pour un management éthique et spirituel,. Défis, cas, outils et questions, Montréal, Fides et Presses HEC, 2000, p. 67-78.

LOUBACK, J.; TEIXEIRA, M.L.M.; BIDO, D. de S. Valores organizacionais e racionalidades: uma visita ao Terceiro Setor. Organ. Soc., Salvador, v. 16, n. 49, p. 225-246, Jun. 2009

MAURINO, S.V.; DOMENICO, S.M.R. de. Realização de valores pessoais no ambiente organizacional (RVP): olhando as relações entre indivíduos e organização para além dos valores pessoais. RAM, Rev. Adm. Mackenzie, São Paulo, v. 13, n. 3, p. 177-213, Jun. 2012

MELO, W.F. de; DOMENICO, S.M.R. de. A influência dos valores organizacionais no desempenho de agências bancárias. Rev. adm. contemp., Curitiba, v. 16, n. 1, p. 137-156, Fev. 2012

MILLIMAN, J.; CZAPLEWSKI, A. J.; FERGUSON, J. Workplace spirituality and employee work attitudes: An exploratory empirical assessment.Journal of Organizational Change Management, v. 16, n. 4, p. 426-447, 2003.

PASCHOAL, T.; TORRES, C.V; PORTO, J.B. Felicidade no trabalho: relações com suporte organizacional e suporte social. Rev. Adm. Contemp. [online]. 2010, vol.14, n.6, pp.1054-1072. ISSN 1982-7849. http://dx.doi.org/10.1590/S1415$\underline{65552010000700005}$.

PASCHOAL, T.; TAMAYO, A. Construção e validação da Escala de bem-estar no trabalho. Aval. psicol. [online]. 2008, vol.7, n.1, pp. 11-22. ISSN 2175-3431.

ROCHA SOBRINHO, F.; PORTO, J.B. Bem-estar no trabalho: um estudo sobre suas relações com clima social, coping e variáveis demográficas. Rev. Adm. Contemp. [online]. 2012, vol.16, n.2, pp.253-270. ISSN 1982-7849. http://dx.doi.org/10.1590/S1415-65552012000200006. 
SILVA, R.R. da. Espiritualidade e religião no trabalho: possíveis implicações para o contexto organizacional. Psicol. cienc. prof., Brasília , v. 28, n. 4, p. 768-779, dez. $2008 \quad$ Disponível $<$ http://pepsic.bvsalud.org/scielo.php?script=sci_arttext\&pid=S141498932008000400009\&lng=pt\&nrm=iso>. Acesso em mai. 2017.

VERGARA, S.C.; MOURA, L.S. Práticas de espiritualidade na gestão de pessoas. In: XXXVI ENCONTRO DA ASSOCIACCÃO NACIONAL DE PÓS-GRADUAÇÃO E PESQUISA EM ADMINISTRAÇÃO, 2012, Rio de Janeiro. Anais. Rio de Janeiro, ANPAD, 2012. 